OPEN ACCESS

Edited by:

Bernard Malissen,

INSERM U1104 Centre

d'immunologie de Marseille-Luminy,

France

Reviewed by:

Graham Anderson,

University of Birmingham,

United Kingdom

Avinash Bhandoola,

National Institutes of Health (NIH),

United States

*Correspondence:

Rhodri Ceredig

rhodri.ceredig@nuigalway.ie

these authors have contributed equally to this work.

Specialty section:

This article was submitted

to T Cell Biology,

a section of the journal

Frontiers in Immunology

Received: 10 April 2018

Accepted: 28 May 2018

Published: 11 June 2018

Citation:

Calvo-Asensio I, Sugrue T, Bosco N, Rolink $A$ and Ceredig R (2018) DN2

Thymocytes Activate a Specific

Robust DNA Damage Response to

lonizing Radiation-Induced DNA

Double-Strand Breaks.

Front. Immunol. 9:1312.

doi: 10.3389/fimmu.2018.01312

\section{DN2 Thymocytes Activate a Specific Robust DNA Damage Response to lonizing Radiation-Induced DNA Double-Strand Breaks}

\author{
Irene Calvo-Asensio ${ }^{1 \dagger}$, Tara Sugrue ${ }^{1 \dagger}$, Nabil Bosco ${ }^{2}$, Antonius Rolink ${ }^{2}$ and Rhodri Ceredig ${ }^{1 *}$ \\ ${ }^{1}$ National University of Ireland, Galway, Ireland, ${ }^{2}$ Department of Biomedicine, University of Basel, Basel, Switzerland
}

For successful bone marrow transplantation (BMT), a preconditioning regime involving chemo and radiotherapy is used that results in DNA damage to both hematopoietic and stromal elements. Following radiation exposure, it is well recognized that a single wave of host-derived thymocytes reconstitutes the irradiated thymus, with donor-derived thymocytes appearing about 7 days post BMT. Our previous studies have demonstrated that, in the presence of donor hematopoietic cells lacking $T$ lineage potential, these host-derived thymocytes are able to generate a polyclonal cohort of functionally mature peripheral $\mathrm{T}$ cells numerically comprising $\sim 25 \%$ of the peripheral $\mathrm{T}$ cell pool of euthymic mice. Importantly, we demonstrated that radioresistant CD44+ CD25+ CD117+ DN2 progenitors were responsible for this thymic auto-reconstitution. Until recently, the mechanisms underlying the radioresistance of DN2 progenitors were unknown. Herein, we have used the in vitro "Plastic Thymus" culture system to perform a detailed investigation of the mechanisms responsible for the high radioresistance of DN2 cells compared with radiosensitive hematopoietic stem cells. Our results indicate that several aspects of DN2 biology, such as (i) rapid DNA damage response (DDR) activation in response to ionizing radiation-induced DNA damage, (ii) efficient repair of DNA double-strand breaks, and (iii) induction of a protective $G_{1} / S$ checkpoint contribute to promoting DN2 cell survival post-irradiation. We have previously shown that hypoxia increases the radioresistance of bone marrow stromal cells in vitro, at least in part by enhancing their DNA double-strand break (DNA DSB) repair capacity. Since the thymus is also a hypoxic environment, we investigated the potential effects of hypoxia on the DDR of DN2 thymocytes. Finally, we demonstrate for the first time that de novo DN2 thymocytes are able to rapidly repair DNA DSBs following thymic irradiation in vivo.

Keywords: DN2 pro-T cells, DNA damage response, ionizing radiation, hypoxia, thymic auto-reconstitution, bone marrow transplantation

\section{INTRODUCTION}

In adults, the bone marrow is the main organ in which hematopoiesis takes place. There, self-renewing, multipotent hematopoietic stem cells (HSCs) reside in a specialized niche and are responsible for continually giving rise to all types of hematopoietic cells (1-4). However, unlike other hematopoietic cells, T lymphocytes are not produced in the bone marrow but rather in the thymus $(5,6)$, 
an organ that provides the optimal microenvironment for supporting all stages of $\mathrm{T}$ cell development and selection $(7,8)$. Under normal physiological conditions, the thymus does not contain self-renewing HSCs. Instead, it is continuously seeded by bone marrow-derived multipotent progenitors that migrate there through the blood $(9,10)$. Once within the thymus, these progenitors receive signals from the thymic stroma that induce them to proliferate and to undergo progressive differentiation into mature, functional, and self-tolerant T cells $(11,12)$.

Within the thymus, developing $\mathrm{T}$ cells, i.e., immature thymocytes, undergo a series of developmental stages that can be distinguished according to the surface expression pattern of the CD4 and CD8 co-receptors. In a normal thymus, $\sim 5 \%$ of thymocytes express neither CD4 nor CD8 (double-negative, DN cells); $\sim 80 \%$ express both CD4 and CD8 (double-positive, DP cells); $10 \%$ are CD4 single-positive (CD4SP), and $\sim 5 \%$ CD8 single-positive (CD8SP) (13). The most immature intra-thymic T cell progenitors are contained within the DN population (14) and according to their surface expression of CD25, CD44, and CD117, DN cells can be further subdivided into four major cellular subsets known as DN1 to DN4. DN1 cells, the most undifferentiated DN subset, can be identified as $\mathrm{CD} 25^{-} \mathrm{CD} 44^{+} \mathrm{CD} 117^{+}$; DN2 cells are $\mathrm{CD} 25^{+} \mathrm{CD} 44^{+} \mathrm{CD} 117^{+}$; DN3 cells are $\mathrm{CD} 25^{+} \mathrm{CD} 44^{\text {low }} \mathrm{CD} 117^{\text {low }}$, and finally DN4 cells, the most differentiated DN subpopulation, are negative for all three markers $\left(\mathrm{CD} 25^{-} \mathrm{CD} 44^{-} \mathrm{CD} 117^{-}\right)(10,14)$.

Upon irradiation, thymic cellularity is dramatically reduced due to the high radiosensitivity of thymocytes (15). However, shortly after exposure to a lethal dose of ionizing radiation (IR), unlike all other hematopoietic and lymphoid organs, there is a single wave of thymic auto-reconstitution that results from the proliferation and differentiation of host-derived intra-thymic radioresistant $\mathrm{T}$ cell precursors (16-19). These cells would also appear to be resistant to the administration of hydrocortisone acetate (20) and were identified by Bosco et al. as DN2 thymocytes (21). These DN2 thymocytes were able to give rise to a cohort of functional mature $\mathrm{T}$ lymphocytes capable of re-constituting $\sim 25 \%$ of the normal peripheral T cell compartment, and displaying a polyclonal $\mathrm{T}$ cell receptor (TCR) repertoire (21). However, the reasons why specifically these DN2 thymocytes are able to survive following thymic irradiation and subsequently resume their normal intra-thymic development post-IR is currently unknown. Therefore, further investigation is required to define the molecular mechanisms underlying the radioresistance of DN2 thymocytes.

Historically, different systems have been developed to study $\mathrm{T}$ cell development, including (i) fetal thymus organ culture (FTOC), (ii) re-aggregated FTOC, (iii) bone marrow chimeras, and (iv) transgenesis $(22,23)$. More recently, in vitro-based expansion and differentiation of immature thymocytes using stromal cell lines ectopically expressing Notch ligands have been used to dissect the signaling events required for $\mathrm{T}$ cell development (24-27). However, in these in vitro systems, the exact combination and intensity of signals delivered by stromal cells are difficult to control. In addition, the presence of stromal cells in these cultures makes detailed genetic and molecular analysis of uniquely $\mathrm{T}$ cellspecific events occurring within cultured progenitors difficult to dissect. The recent development of a stromal cell-free pro-T cell culture system in the laboratory of Prof. Antonius Rolink has proven to be a very useful tool for studying the minimal requirements necessary for T-cell commitment and differentiation (28). This stromal cell-free culture system commonly known as "The Plastic Thymus" is based on the immobilization of a DL4human $\mathrm{IgG}_{1}-\mathrm{Fc}$ (DL4-Fc) fusion protein to the surface of plastic tissue culture plates pre-coated with a monoclonal anti-human $\mathrm{IgG}_{1}-\mathrm{Fc}$ antibody (28). In addition, the culture medium is supplemented with IL-7 and SCF, allowing the long-term in vitro maintenance and expansion of purified DN2 thymocytes (29). Importantly, the pro-T cells generated and expanded in vitro using this methodology (i) retain their normal functionality, (ii) can be genetically manipulated, and (iii) are able to reconstitute T cell compartments of irradiated recipient mice (29). Therefore, "The Plastic Thymus" represents a novel technology with which to study purified DN2 thymocytes at the molecular level, something that is otherwise technically difficult to do in the normal mouse thymus in vivo due to the limited numbers of pro-T cells, particularly DN1 and DN2 cells.

Cellular responses to IR exposure mainly occur due to its detrimental impact on the genome integrity of exposed cells. IR-induced DNA damage can occur due to energy deposited directly onto DNA, or indirectly due to the generation of free radicals within cells, which collectively lead to the modification and/or breakage of DNA strands. The most genotoxic IR-induced DNA lesions are DNA double-strand breaks (DNA DSBs). The maintenance of genomic integrity is essential for cellular survival and for preventing carcinogenesis. Consequently, cells have developed an integrated series of signaling networks, known collectively as the DNA damage response (DDR), to mount biological responses to genotoxic insult. At the molecular level, the DDR consists of (i) sensor proteins that recognize sites of damaged DNA, (ii) transducer proteins that amplify DNA damage signals, and (iii) effector proteins, required for the desired biological response(s) including DNA repair, transient delays in cell cycle progression (termed checkpoints), transcriptional and epigenetic programs, apoptosis, and senescence $(30,31)$.

Similar to DN2 thymocytes, mesenchymal stromal cells (MSCs) that support hematopoiesis in the bone marrow, and thymic epithelial cells (TECs), which support thymopoiesis in the thymus, are also relatively radioresistant (32-34). In previous studies, we have demonstrated that the activation of the DDR plays important roles in enabling in vitro irradiated MSCs and TECs to quickly respond to IR-induced DNA damage and to engage molecular pathways that promote rapid DNA DSB repair, DNA damage checkpoint activation, and cell survival $(34,35)$. Therefore, using the methods we have previously applied to investigate the DDR of irradiated MSCs, we aimed herein to investigate the role of the DDR in mediating the radioresistance of DN2 thymocytes.

In this study, we have used the "Plastic Thymus" culture system to dissect DN2 radiobiology at the molecular level. For comparative purposes, and as a model of a radiosensitive hematopoietic cell type, we have also used a NUP98-HOXB4 expressing HSC line (refer to Section "Materials and Methods" for further information). We demonstrate for the first time that in response to IR-induced DNA DSBs, DN2 thymocytes execute a robust DDR 
leading to the resolution of these lesions and to cell survival. Furthermore, we also demonstrate that this robust DDR is also executed by DN2 thymocytes in vivo following thymic irradiation. Taken together, our results from both in vitro and in vivoderived cells indicate that the DDR of DN2 thymocytes harbors characteristic features favoring their ability to rapidly respond to IR-induced DNA damage and repair DNA lesions, likely playing a key role in their relative radioresistance.

\section{MATERIALS AND METHODS}

\section{Cell Culture and Treatments}

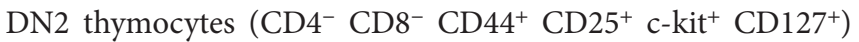
were isolated from the thymi of 4 - to 6 -week-old C57BL/6 mice as previously described (10) and sorted using a BD FACS Aria ${ }^{\circledR}$ cell sorter. As previously discussed, the "Plastic Thymus" culture system allows long-term expansion of DN2 pro-T cells in vitro in the absence of stromal cells (29). Details of this culture system are described in Section Supplementary Methods in Supplementary Material and shown graphically in Figure S1 in Supplementary Material. DN2 thymocytes were shown to maintain their characteristic cell surface phenotype $\left(\mathrm{CD} 44^{+} \mathrm{CD} 25^{+} \mathrm{CD} 117^{+}\right)$when cultured long-term in $21 \% \mathrm{O}_{2}$ (Figure S2 in Supplementary Material).

To study HSCs, a NUP98-HOXB4 HSC (NH-HSC) line was generated from $\mathrm{C} 57 \mathrm{BL} / 6$ mice following the protocol established by Sauvageau et al. (36) and subsequently optimized by Ruedl et al. (37). The NH-HSC line obtained following this protocol was confirmed to display the surface phenotype: CD $45^{+} \mathrm{Lin}^{-} \mathrm{c}-\mathrm{kit}^{+}$ Sca- $1^{+}$CD $11 c^{-}$CD 19- B220- CD4 $4^{-} \mathrm{CD}^{-}$and to be capable of successfully re-constituting all hematopoietic lineages in sublethally irradiated mice (38). For the purposes of this study, NH-HSCs were maintained in SF-IMDM (Gibco) supplemented with 5\% forward light scatter (FCS) (Gibco), 3\% v/v IL-6containing supernatant, $0.1 \mu \mathrm{g} / \mathrm{ml} \mathrm{SCF}$ and $0.2 \% \mathrm{v} / \mathrm{v}$ Ciproxin ${ }^{\circledR}$ (Bayer Pharmaceutical) at $37^{\circ} \mathrm{C}$ [as described in Ref. (38)], in either normoxia $\left(21 \% \mathrm{O}_{2}\right)$ or hypoxia $\left(5 \% \mathrm{O}_{2}\right)$.

$\gamma$-Irradiation at the indicated doses was performed using a Gammacell 40 irradiator containing a ${ }^{137} \mathrm{Cs}$ source at a dose rate of $\sim 80 \mathrm{cGy} / \mathrm{min}$.

\section{Mice}

C57BL/6 mice were bred under pathogen-free conditions at the Centre for Biomedicine at the University of Basel. All animal experiments were carried out within institutional guidelines (authorization numbers 1886 and 1888 from Kantonales Veterinäramt, Basel).

\section{Isolation and Sorting of Mouse CD4/CD8 DN 1-3 Subpopulations}

Double-negative cells were isolated from 5 thymi per time point after irradiation ( 9 Gy) and sorted according to their cell surface phenotypes as previously described (10) and outlined in Section Supplementary Methods and Figure S3 in Supplementary Material. DN1 were sorted as CD117 $7^{\text {high }}, \mathrm{CD} 25^{-}$and $\mathrm{CD} 44^{\text {high }}$, $\mathrm{DN} 2$ as CD117 $7^{\text {high }}, \mathrm{CD} 25^{+}$and $\mathrm{CD} 44^{\text {high }}$ and $\mathrm{DN} 3$ as CD117 low,
CD25 $5^{+}$and CD44 ${ }^{\text {low }}$ (Figure S3 in Supplementary Material) (10). Sorted cells were pelleted, re-suspended in $100 \mu \mathrm{IMDM}$, and centrifuged onto poly-L-lysine-coated microscope slides using a Cytospin ${ }^{\circledR}$ centrifuge (Shandon) for immunofluorescence staining as described below.

\section{Clonogenic Survival Assay}

DN2 and NH-HSC were irradiated at 0.5-4 Gy, seeded into 6 -well plates at a concentration of 50,000 cells/well, harvested 3 or 5 days post-irradiation (for NH-HSCs and DN2 cells, respectively) and viable cell numbers were counted in duplicate using a hemocytometer and Trypan blue for exclusion of dead cells. The time-points for cell counting were selected based on the fact that DN2 thymocytes proliferated more slowly than NH-HSCs (Figure S4 in Supplementary Material). The percentage survival of each cell type was then determined by normalizing the number of cells quantified from irradiated versus control (un-irradiated) cultures.

\section{Flow Cytometry Methods}

Cells were harvested and counted prior to staining following the different protocols described below. Cells were then analyzed using a BD FACS Canto ${ }^{\circledR}$ or BD FACS Calibur flow cytometer (BD Biosciences) and FlowJo ${ }^{\circledR}$ data analysis software (Tree Star Inc., OR, USA). For surface labeling, cells were pelleted and resuspended in FACS buffer (2\% FCS, 0.05\% Sodium Azide, PBS) at $5 \times 10^{6}$ cells $/ \mathrm{ml}$. Then, $5 \times 10^{5}$ cells $/$ sample were stained for $20 \mathrm{~min}$ with the appropriate primary antibodies or isotype controls. To reveal cells stained with biotin-labeled antibodies, the cells were subsequently washed in FCS-free FACS buffer, stained for $10 \mathrm{~min}$ with fluorescently labeled streptavidin, washed, and then analyzed.

For cell cycle analysis, cells were labeled for $1 \mathrm{~h}$ with $25 \mu \mathrm{M}$ 5 '-bromo-deoxyuridine (BrdU) (Sigma-Aldrich), washed with PBS, and re-suspended in growth medium. Cells were harvested at the indicated time points post-irradiation (4 Gy), fixed in ice-cold $70 \%$ ethanol, and stained with anti-BrdU and FITC-conjugated anti-mouse IgG antibodies and propidium iodide (PI)/RNase staining buffer (BD Biosciences) as previously described (35). The progression of cells through the cell cycle was analyzed by measuring the percentage BrdU-positive cells in each $\mathrm{G}_{1}$ phase until $24 \mathrm{~h}$ post IR using a BD FACS Canto ${ }^{\circledR}$ flow cytometer (BD Biosciences) and FlowJo ${ }^{\circledR}$ software (Tree Star Inc., OR, USA).

Information regarding all antibodies used for flow cytometry can be found in Section Supplementary Methods in Supplementary Material.

\section{Real-Time PCR}

Total RNA was isolated from cells by TRIzol ${ }^{\circledR}$ Reagent (Life Technologies)-and cDNA was generated using Applied Biosystems' High-Capacity cDNA Reverse Transcription Kit according to the manufacturer's instructions. 10-20 ng of cDNA was used as template in semi-quantitative real-time PCR reactions with specific primers on a Step One Plus Real-Time PCR System (Applied Biosystems). Reactions were prepared with TaqMan ${ }^{\circledR}$ gene expression master mix (Thermo Fisher Scientific) using predesigned TaqMan $^{\circledR}$ gene expression assays for amplification 
of mouse Lig4 (DNA Ligase 4), Prkdc (DNA-PKcs), Rad51, and $\beta$-actin (Thermo Fisher Scientific). Gene expression changes were determined using the $\Delta \Delta \mathrm{Ct}$ method, using $\beta$-actin as a housekeeping gene for normalization according to the primer efficiencies previously calculated.

\section{Western Blotting}

Whole cell extracts were prepared from control or irradiated cells at the indicated time points post-irradiation by direct addition of $5 \mu \mathrm{l}$ of $4 \times$ Laemmli buffer per 100,000 cells that we previously harvested from culture by centrifugation, washed with ice-cold PBS, and counted. Cells were disaggregated into the Laemmli buffer, heated at $95^{\circ} \mathrm{C}$ for $5 \mathrm{~min}$, and sonicated (20\% amplitude for $3 \mathrm{~s}$ ) prior to separation using SDS-PAGE gels and transferred to nitrocellulose membranes. Chemiluminescence was detected using SuperSignal West Pico Chemiluminescent Substrate (Thermo Fisher Scientific) and medical x-ray film (Konica Minolta Medical and Graphic Imaging Inc.). Information regarding all antibodies used for western blotting can be found in Section Supplementary Methods in Supplementary Material.

\section{Immunofluorescence Staining and Microscopy}

Double-negative cells were spun onto poly-L-lysine-coated microscope slides using a Cytospin ${ }^{\circledR}$ centrifuge (Shandon), fixed in $4 \%$ paraformaldehyde (Sigma-Aldrich), and subsequently permeabilized in $0.1 \%$ Triton $^{\circledR}$-X 100 solution. Nuclei were then stained for $\gamma \mathrm{H} 2 \mathrm{AX}$ IR-induced foci (IRIF) as previously described (35). Image Z-stacks were captured using $60 \times$ magnification on a Leica SP5 integrated microscope system (Leica Microsystems). Images were deconvoluted using the Huygens Software by Scientific Volume Imaging. Image Z-stacks were projected using the maximal intensity method using Fiji (39). Customized macros for Fiji were used to adjust the projected images and the number of $\gamma \mathrm{H} 2 \mathrm{AX}$ IRIF per nucleus were counted blind. Information regarding all antibodies used for western blotting can be found in Section Supplementary Methods in Supplementary Material.

\section{RESULTS}

\section{DN2 Thymocytes Are Relatively Radioresistant In Vitro}

We first investigated the effects of irradiation on the survival of DN2 thymocytes in vitro, using $\mathrm{NH}-\mathrm{HSCs}$ as a radiosensitive control. To do so, DN2 and NH-HSC were irradiated at 0-4 Gy and cultured for 3 (NH-HSC) or 5 days (DN2) before counting surviving cells. As shown in Figure 1, the radioresistance of DN2 and NH-HSC was comparable at IR doses of 0.5-2 Gy. However, at $4 \mathrm{~Gy}$, the radioresistance of DN2 cells was found to be 10 -fold greater than that of $\mathrm{NH}-\mathrm{HSC}(\sim 18.7 \% \mathrm{DN} 2$ survival versus $\sim 1.8 \%$ NH-HSC survival) (Figure 1).

\section{DN2 Thymocytes Activate DNA Damage Checkpoints In Vitro}

As previously mentioned, the DDR plays a key role in determining whether a cell survives or dies following exposure to genotoxic

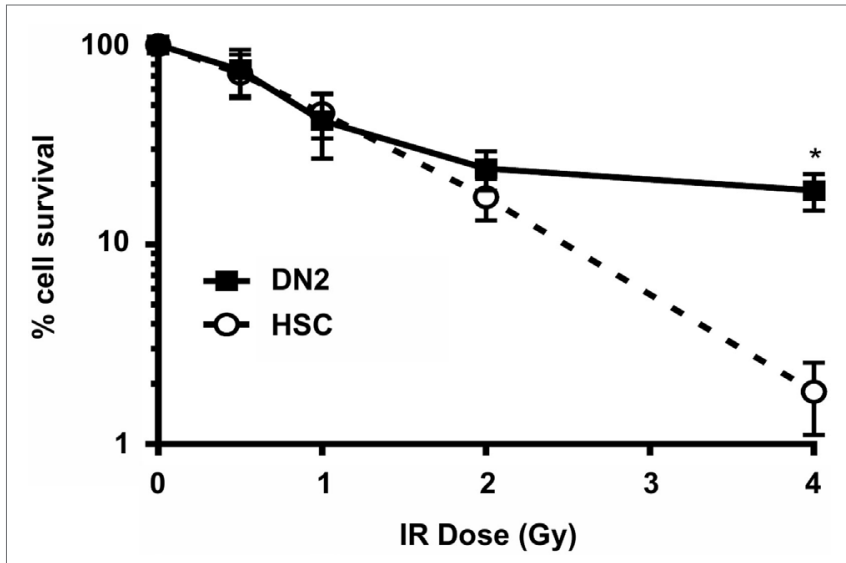

FIGURE 1 | Double-negative (DN)2 thymocytes survive $\boldsymbol{\gamma}$-irradiation in vitro. Clonogenic survival assays of mouse DN2 thymocytes and $\mathrm{NH}$-hematopoietic stem cells (HSCs) $\gamma$-irradiated at 0.5-4 Gy and cultured for 3 or 5 days (depending on the cell type). Error bars represent mean $\pm \mathrm{SD}, n=3$. ${ }^{*} p<0.05$, two-way ANOVA analysis with Sidak's multiple comparisons test.

agents, such as IR. The activation of DNA damage checkpoints during the cell cycle acts to prolong the time in which a given cell can execute mechanisms to try and resolve genomic damage and promote its survival. The difference in the long-term survival between DN2 and NH-HSC suggested that these DNA damage checkpoints may be differentially executed between these two cell types. To investigate this, the cell cycle progression of BrdU pulse-labeled DN2 and NH-HSCs was analyzed at various time points post $4 \mathrm{~Gy}$ irradiation by flow cytometry (Figure 2A). By co-staining these cells with an anti-BrdU antibody and PI, the $G_{1}$, $\mathrm{S}$, and $\mathrm{G}_{2} / \mathrm{M}$ phases of the cell cycle (Figure $2 \mathrm{~A}$, top left panel) can be clearly distinguished. Furthermore, the progression of BrdUlabeled (S phase) cells through the cell cycle and their return to the $\mathrm{G}_{1}$ phase can be monitored (Figure 2A). Importantly, under control conditions (no irradiation, $0 \mathrm{~Gy}$ ), BrdU labeling itself did not cause significant toxicity to either DN2 or NH-HSCs (Figure S4 in Supplementary Material). Under normal conditions (0 h), $\sim 16 \%$ DN2 population were in S phase (BrdU-positive) compared with $\sim 56 \%$ NH-HSC (Figure 2B). Furthermore, $78 \%$ DN2 population was found to be in $\mathrm{G}_{1}$ phase, compared with $\sim 41 \%$ NH-HSC population (Figure 2B). These results correlate with the increased rate of cell cycle progression observed in NH-HSCs, compared with DN2 cells (Figure S4 in Supplementary Material).

Dramatic differences in the ability of DN2 and NH-HSC to activate cell cycle arrest were observed post-irradiation. Strikingly, DN2 thymocytes that were in $\mathrm{G}_{1}$ phase at the time of irradiation were largely maintained over time ( $78 \%$ in $\mathrm{G}_{1}$ at $0 \mathrm{~h}$ versus $\sim 68.4 \%$ in $\mathrm{G}_{1}$ at $36 \mathrm{~h}$ post IR) (Figure $2 \mathrm{C}$ ). This strongly contrasted with $\mathrm{NH}-\mathrm{HSC}$ shose $\mathrm{G}_{1}$ population reduced rapidly post-irradiation from $\sim 41 \%$ at $0 \mathrm{~h}$ to $\sim 0.8 \%$ at $36 \mathrm{~h}$ post IR (Figure 2C). This reduction in $\% \mathrm{G}_{1}$ cells was likely due to the activation of cell death as evidenced by the appearance of a large sub-G $\mathrm{G}_{1}$ population in NH-HSC profiles post-irradiation (Figure 2E and indicated in Figure $2 \mathbf{A}$ by black arrows in bottom panels). BrdU-labeled DN2 cells accumulated as a cohort in late $S / G_{2}$ phases until $8 \mathrm{~h}$ post $I R$, indicative of the activation 
A Time post $4 \mathrm{~Gy}$ irradiation (h)
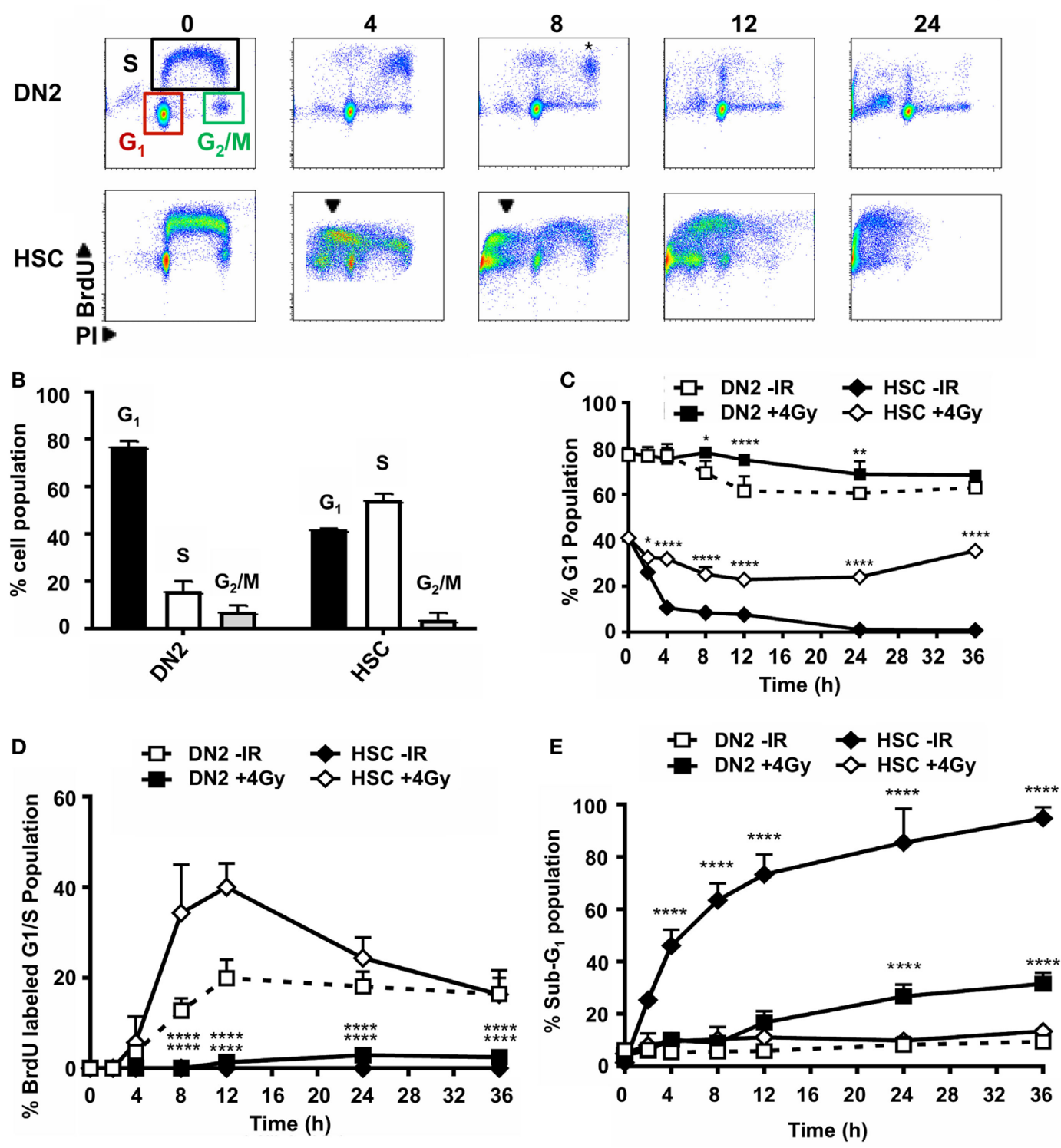

FIGURE 2 | Double-negative (DN)2 thymocytes activate DNA damage checkpoints. (A) Representative cytograms of DN2 and NH-hematopoietic stem cells (HSCs) at 0-24 h post 4 Gy irradiated and stained for bromo-deoxyuridine (BrdU) incorporation and DNA content using propidium iodide (PI). Colored boxes are used to indicate $G_{1}, S$, and $G_{2} / M$ phase cells under control conditions; black arrowheads indicate sub- $G_{1}$ cells and * indicates cohort of BrdU-labeled DN2 cells accumulated in late $\mathrm{S} / \mathrm{G}_{2}$. (B) Quantification of the percentage DN2 and NH-HSCs in each phase of the cell cycle under normal conditions. (C) Quantification of the percentage $\mathrm{G}_{1} \mathrm{DN} 2$ cells and NH-HSCs at 0-36 h post-irradiation or under normal conditions. (D) Quantification of the percentage BrdU-labeled $\mathrm{G}_{1} /$ early $\mathrm{S}$ phase DN2 cells and NH-HSCs at 0-36 h post-irradiation or under normal conditions. (E) Quantification of the percentage sub-G $\mathrm{DN}^{\mathrm{N}}$ cells and NH-HSCs at 0-36 $\mathrm{h}$ post-irradiation or under normal conditions All cytograms and graphs are representative of three independent experiments. Error bars represent mean \pm SD, $n=3$, ${ }^{*} p<0.05,{ }^{* *} p<0.01,{ }^{* * *} p<0.0001$. Two-way ANOVA analysis with Tukey's multiple comparisons test was performed on the following conditions (i) DN2-ionizing radiation (IR) versus DN2 + 4 Gy and (ii) HSC-IR versus HSC + 4 Gy.

of intra-S-phase and $\mathrm{G}_{2}$ checkpoints (32) (Figure 2A, ${ }^{\star}$ in top $8 \mathrm{~h}$ panel). However, BrdU labeled DN2 thymocytes did not re-enter cell cycle following $\mathrm{G}_{2}$ checkpoint activation and likely entered cell death, similar to NH-HSCs (Figure 2B, top $24 \mathrm{~h}$ panel). Similar to the $\mathrm{G}_{1} \mathrm{NH}-\mathrm{HSC}$ population, BrdU labeled NH-HSCs also underwent cell death post IR (Figures 2A,E). Taken together, these results indicate that in the immediate response to irradiation, DN2 thymocytes activate DNA damage checkpoints more robustly than NH-HSCs which instead seem to directly revert to activating cell death. Interestingly, these results also demonstrate that DN2 thymocytes that survive long-term post IR originate primarily from cells in $G_{1}$ phase of the cell cycle, indicating that DN2 thymocytes induce a protective $G_{1} / S$ checkpoint in response to IR-induced DNA damage. 


\section{DN2 Thymocytes Activate a Robust DDR Post-Irradiation}

The contrasting cellular responses of DN2 thymocytes versus NH-HSCs to IR-induced DNA Damage (strong induction of $\mathrm{G}_{1}$ arrest in irradiated DN2 thymocytes versus apoptosis in NH-HSCs) suggested that the molecular DDR pathways may be differentially executed in these two cell types. To determine whether DN2 and HSC differentially activate the DDR in response to IR-induced DNA DSBs, H2AX Ser139 phosphorylation ( $\gamma \mathrm{H} 2 \mathrm{AX}$, DNA DSB marker); p53 stabilization; and p21 and Puma expression were analyzed over a 24-h time-course (Figure 3A). Maximal H2AX phosphorylation was detected in DN2 at $1 \mathrm{~h}$ post IR, whereas it was delayed in HSC and accumulated until 4 h post IR (Figure 3A). p53 was stabilized, and p21 and Puma expression were induced, in irradiated DN2 and HSC, indicating that DDR pathways were intact in these cell types in vitro. However, in contrast to HSC, p53 stabilization and induced expression of the pro-apoptotic protein, Puma, were transient in irradiated DN2 (Figure 3A). Furthermore, p21 expression was strongly induced in DN2 at early $(1-4 \mathrm{~h})$ time-points post IR whereas it was weakly induced in HSC at later time-points (12 and $24 \mathrm{~h}$ ) (Figure 3A). Taken together, these results indicate that irradiated DN2 thymocytes rapidly induce the $\mathrm{p} 53 / \mathrm{p} 21$ signaling cascade following DNA DSB generation which likely contributes to the ability of this cell type to induce a protective $\mathrm{G}_{1} / \mathrm{S}$ checkpoint, promoting their survival. Similar to previous observations seen in other radiosensitive cell types such as DP thymocytes (35), NH-HSCs appear to rapidly revert to inducing apoptosis, rather than protective DNA damage checkpoints, as evidenced by the long-term persistence of Puma and p53 stabilization in the presence of DNA DSBs (Figure 3A).

Western blot analysis of controlDN2 and HSC whole cell extracts revealed that DN2 expressed higher endogenous levels of the DNA DSB sensor protein, ATM (Figure 3B) and of the DNA DSB repair via NHEJ proteins, DNA-PK $\mathrm{Cs}_{\mathrm{cs}}$ and 53BP1, than NH-HSCs (Figures 3B,C). The expression levels of the DNA DSB mediator protein, Chk2, were found to be comparable between DN2 and $\mathrm{NH}-\mathrm{HSC}$, whereas endogenous levels of Rad51, a protein playing a key role in DNA DSB repair via homologous recombination was increased in NH-HSCs in comparison with DN2 cells (Figure 3C). In addition, compared with $\mathrm{NH}-\mathrm{HSC}, \mathrm{DN} 2$ cells were found to

A

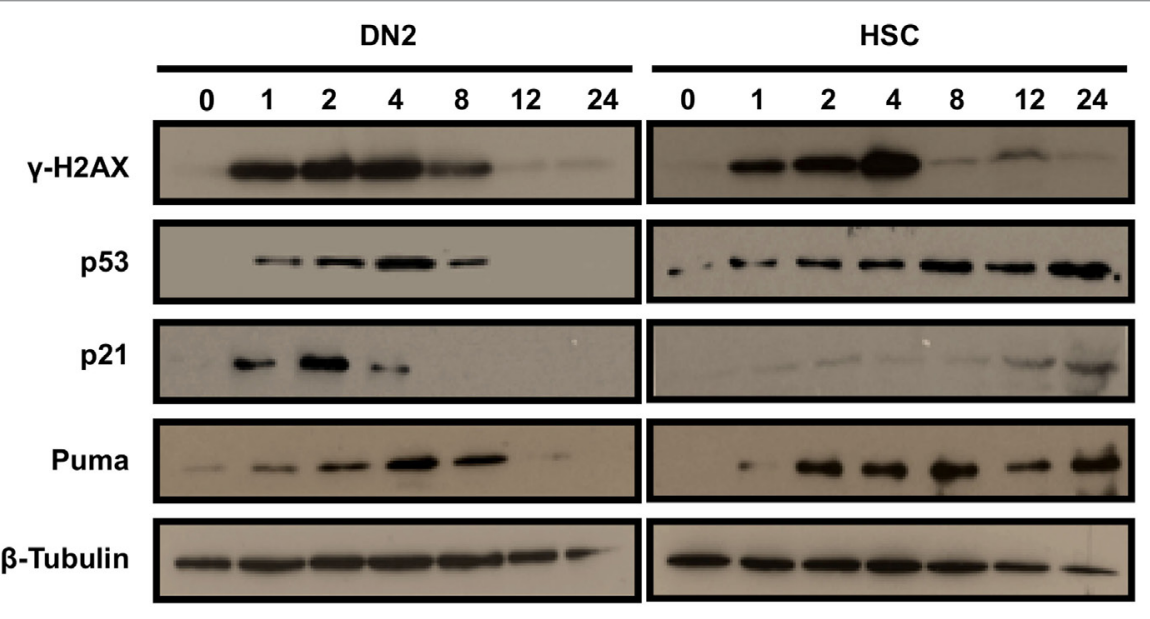

B

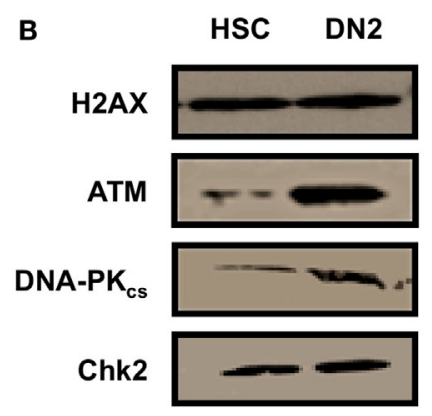

c

HSC

DN2

D

HSC

DN2
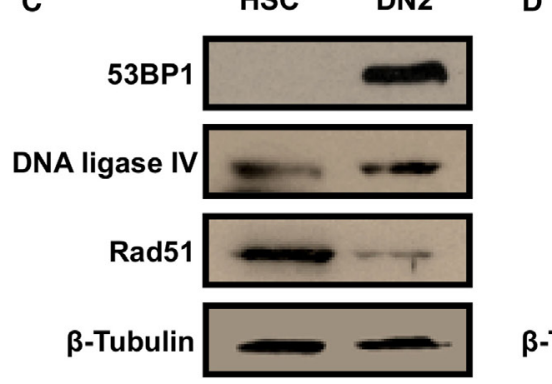

$\mathrm{Bcl}-2$

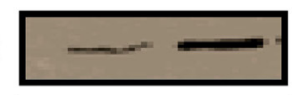

$\beta$-Tubulin

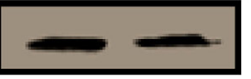

FIGURE 3 | DN2 thymocytes activate a robust DNA damage response following $\gamma$-irradiation. Western blot analysis of (A) H2AX (Ser139) phosphorylation ( $\gamma \mathrm{H} 2 \mathrm{AX}$ - marker of DNA double-strand breaks), p53 stabilization; and p21 and Puma expression in DN2 cells and NH-hematopoietic stem cells (HSCs) at 0-24 $\mathrm{h}$ post 4 Gy irradiation. Western blot analysis of total endogenous levels of (B) of H2AX, ATM, DNA-PKcs and Chk2; (C) of 53BP1, DNA ligase IV and Rad51; and (D) of Bcl-2, Bcl-XL, and Bim in un-irradiated (control) DN2 cells and NH-HSCs. $\beta$-Actin and $\beta$-tubulin were used as internal controls. All images are representative of one of three independent experiments. 
express higher levels of anti-apoptotic proteins, $\mathrm{Bcl}-2$ and $\mathrm{Bcl}-\mathrm{xL}$, and of the pro-apoptotic protein, Bim (Figure 3D).

\section{Hypoxia Differentially Impacts on the DNA DSB Repair Capacity of DN2 Thymocytes and NH-HSCs}

Our group has previously shown that the capacity of irradiated mouse MSCs and TECs to repair DNA DSBs is modulated by hypoxia, correlating with an effect on their intrinsic radioresistance $(34,40)$. Similar to the bone marrow, the thymus also consists of a hypoxic environment and therefore we were interested in investigating whether hypoxia may affect the radiobiology of DN2 thymocytes. To this end, we first investigated the effect of hypoxia on cell cycle checkpoint activation in irradiated DN2 thymocytes and $\mathrm{NH}-\mathrm{HSCs}$ using the irradiation conditions studied previously. Culture in hypoxia did not affect the cell cycle progression of neither DN2 thymocytes nor NH-HSCs in normal growth conditions (Figure 4A). In addition, hypoxia exposure did not significantly impact on DNA damage checkpoint activation and recovery of $\mathrm{DN} 2$ thymocytes in response to irradiation (Figures 4B,D). However, culture under hypoxic conditions resulted in a significantly higher proportion of NH-HSCs being able to survive and resume the cell cycle,

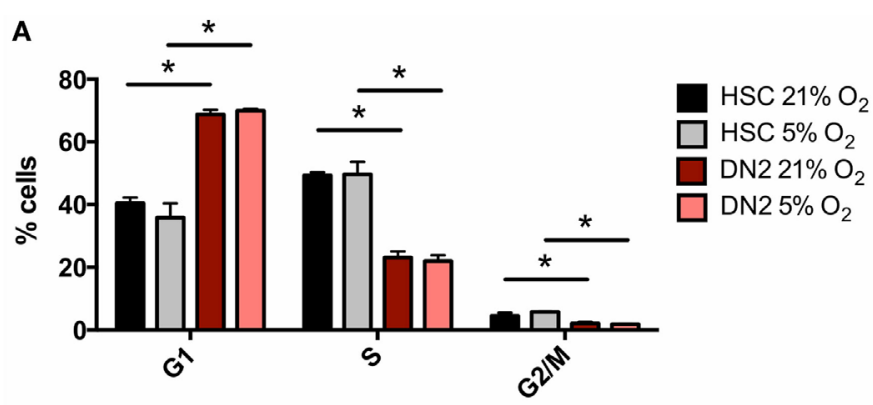

B

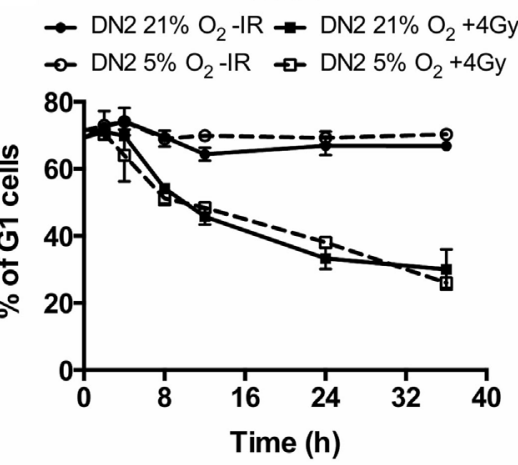

D

DN2

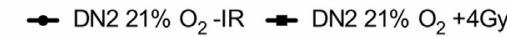

$\rightarrow$ DN2 $5 \% \mathrm{O}_{2}-\mathrm{IR} \rightarrow \mathrm{DN} 25 \% \mathrm{O}_{2}+4 \mathrm{~Gy}$

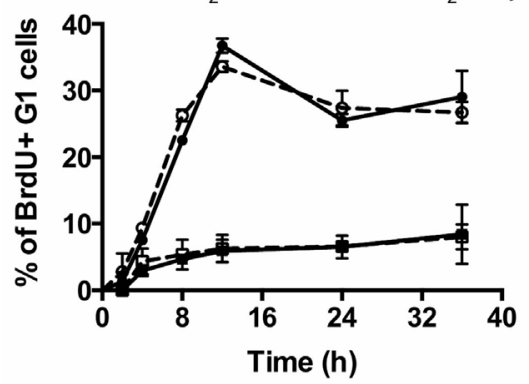

C

HSC

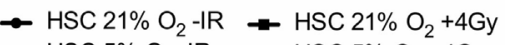

$\rightarrow \mathrm{HSC} 5 \% \mathrm{O}_{2}-\mathrm{IR} \rightarrow \mathrm{HSC} 5 \% \mathrm{O}_{2}+4 \mathrm{~Gy}$

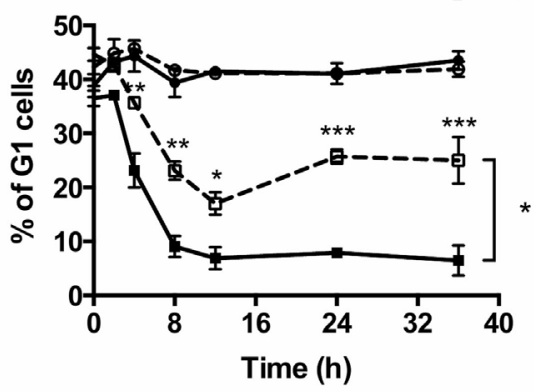

E

HSC
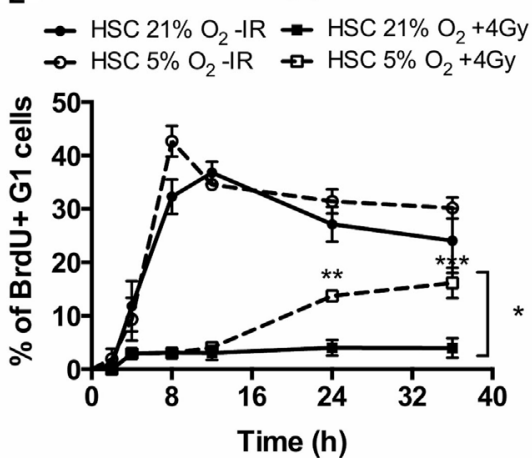

FIGURE 4 | Cell cycle checkpoint activation of normoxic and hypoxic DN2 thymocytes. (A) Comparison of the percentage of cells in each phase of the cell cycle in $\mathrm{NH}$-hematopoietic stem cell (HSC) and DN2 cells cultured in 21 or $5 \% \mathrm{O}_{2} .{ }^{*} p<0.05$, multiple $t$-tests with Holm-Sidak post-test correction. Quantification of average percentage of $\mathrm{G}_{1}$ phase (B) DN2 and (C) NH-HSC cells cultured in either 21 or $5 \% \mathrm{O}_{2}, 0-36 \mathrm{~h}$ post bromo-deoxyuridine (BrdU) pulse, with or without treatment with 4 Gy of ionizing radiation (IR). ${ }^{\star} p<0.05,{ }^{* \star} p<0.01,{ }^{* \star *} p<0.001$, two-way ANOVA analysis with Bonferroni post-test correction, $n=3$. Quantification of average percentage of BrdU-labeled $\mathrm{G}_{1}$ phase (D) DN2 and (E) NH-HSC cells cultured in either 21 or $5 \% \mathrm{O}_{2}, 0-36 \mathrm{~h}$ post BrdU pulse, with or without treatment with 4 Gy of IR. ${ }^{* *} p<0.01,{ }^{* \star *} p<0.001$, two-way ANOVA analysis with Bonferroni post-test correction, $n=3$. 
compared to their normoxic counterparts (Figures 4C,E; Figure S5 in Supplementary Material).

In addition, the kinetics of $\gamma \mathrm{H} 2 \mathrm{AX}$ induction and resolution in DN2 and NH-HSC cultured in normoxia and hypoxia was analyzed at different time-points post-irradiation (Figure 5A). The kinetics of $\gamma \mathrm{H} 2 \mathrm{AX}$ induction in both cell types at early time-points post-irradiation were found to be unaffected by oxygen tension (Figure 5A). However, in hypoxia, faster resolution of $\gamma \mathrm{H} 2 \mathrm{AX}$ phosphorylation was observed in the case of NH-HSCs, which may indicate faster repair of DNA DSBs. By contrast, although as previously shown the peak of $\gamma \mathrm{H} 2 \mathrm{AX}$ levels in DN2 cells occurs earlier, culture under hypoxic conditions results in slower kinetics of DSB repair in these cells, opposite to the results obtained with $\mathrm{NH}-\mathrm{HSCs}$.

In light of the previous results (Figure 3B), the effects of hypoxia on the endogenous expression levels of DNA repair and apoptotic factors in NH-HSCs and DN2 cells were also analyzed (Figures 5B,D). Culture under different oxygen levels did not cause significant changes in mRNA expression level of any of the DNA repair factors analyzed (DNA-PKcs, DNA ligase IV, and Rad51) in both cell types (Figure 5B). Similar to previous results (Figure 3B), DN2 thymocytes expressed (i) higher endogenous levels of DNA Ligase IV and 53BP1 and (ii) lower levels of Rad51 compared with NH-HSCs (Figures 5B,C). However, hypoxic DN2 cells had decreased levels of both proteins in comparison to their normoxic counterparts, correlating with the lower DSB repair efficiency detected in these cells in hypoxia (Figure 5A).

Protein levels of the anti-apoptotic factors Bcl-2 and Mcl-1 and the pro-apoptotic factors Bim and Puma were also analyzed. Interestingly, compared with normoxic cultures, culture of $\mathrm{NH}-\mathrm{HSC}$ under hypoxic conditions resulted in a large increase

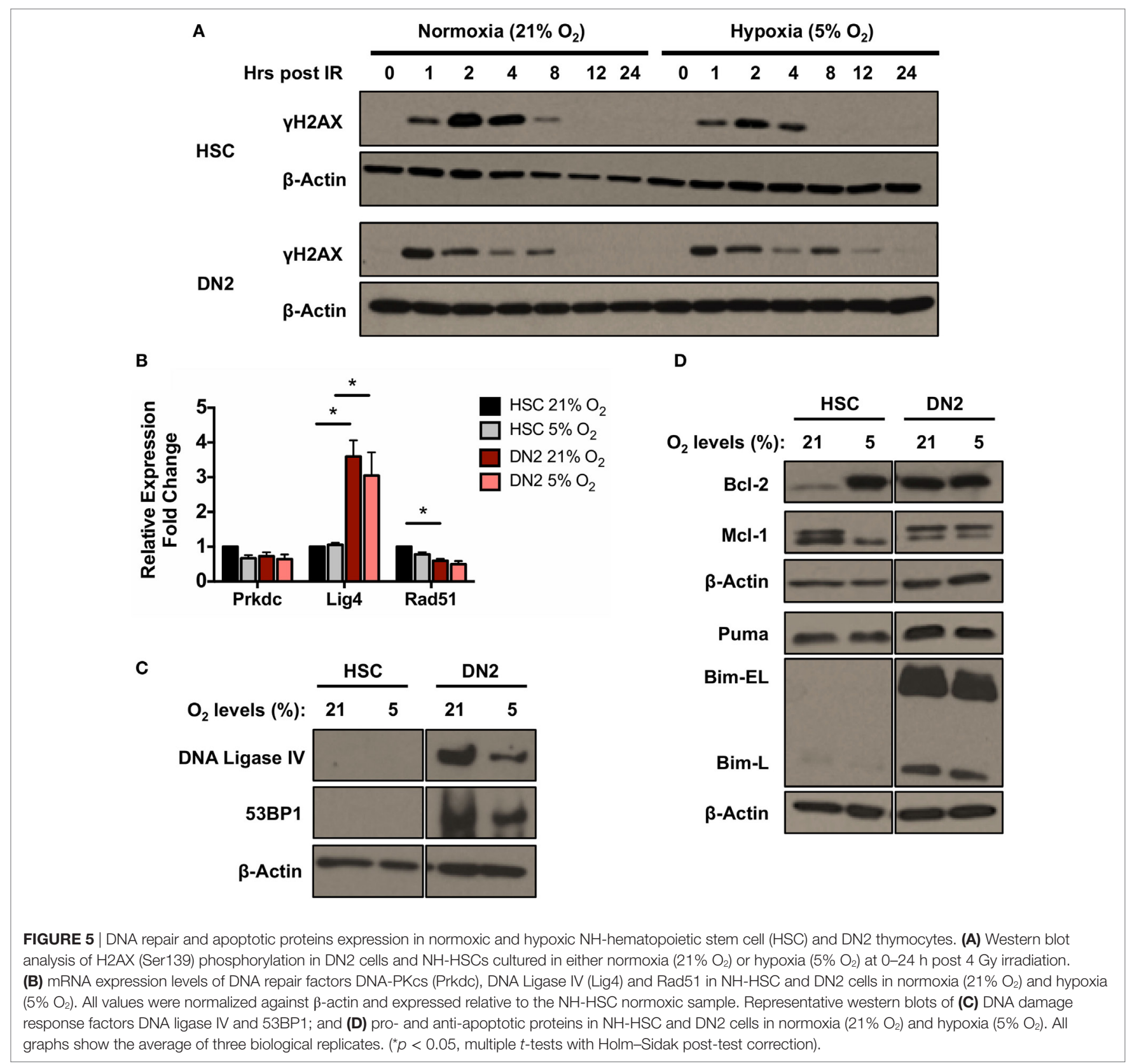


in endogenous $\mathrm{Bcl}-2$ protein levels (Figure 5D). In line with this, the radioresistance of $\mathrm{NH}-\mathrm{HSC}$ was found to be increased in hypoxic conditions (Figure S5 in Supplementary Material). In normoxia, DN2 cells expressed high levels of endogenous Bcl-2 protein, similar to those of hypoxic NH-HSCs, but this was not affected by oxygen tension. Interestingly, NH-HSCs and DN2 cells showed different patterns of expression of the two Mcl-1 bands detected by Western blotting. While DN2 cells express higher levels of the upper band regardless of the oxygen levels, NH-HSC express equal levels of both bands in normoxia, but show preferential expression of the lower one in hypoxia (Figure 5D). With regard to the pro-apoptotic proteins, while the levels of Puma were similar between DN2 and HSC, DN2 showed much higher levels of the Bim-EL and Bim-L isoforms.

\section{In Vivo Response of DN Pro-T Cell Subpopulations to IR}

Until now, we have demonstrated that the execution of the DDR and DNA DSB repair plays important roles in mediating the radioresistance of DN2 thymocytes in vitro. Therefore, our final objective was to determine whether DN2 thymocytes activate the $\mathrm{DDR}$ in vivo in response to irradiation. To do so, $\mathrm{DN} 2$ pro- $\mathrm{T}$ cells and their radiosensitive progenitors (DN1 cells) and progeny (DN3 cells) were isolated from either control or irradiated mice at different time-points following $9 \mathrm{~Gy}$ of whole body irradiation as graphically described in Figure S3A in Supplementary Material. The isolated cells were subsequently stained with specific antibodies to CD25, CD44, cKit, and CD3 and sorted into DN1, DN2, and DN3 subpopulations (Figure S3B in Supplementary Material). The numbers of both DN1 and DN3 pro-T cells recovered from the thymi dramatically dropped after IR treatment, whereas the number of DN2 pro-T cells remained higher in proportion at all time-points post-IR (Figures 6A,B). Interestingly, CD117 (cKit) surface expression by DN cells decreased over time following the IR treatment, an effect that was not correlated with changes in cell size, as measured by FCS measurements (Figure S6 in Supplementary Material). Sorted DN subpopulations were then analyzed at different time-points post IR for the appearance and resolution of $\gamma \mathrm{H} 2 \mathrm{AX}$ IRIF (Figures 6C,D). Similar to our findings in vitro (Figure 3A), in vivo-derived DN2 cells activated the DDR very quickly post IR, as evidenced by the peak in $\gamma \mathrm{H} 2 \mathrm{AX}$
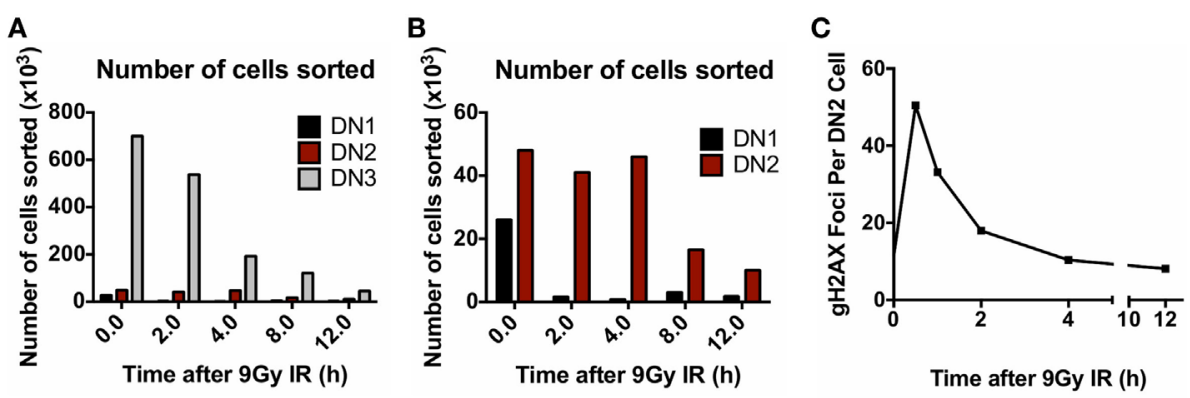

D

Time after 9Gy IR (h)

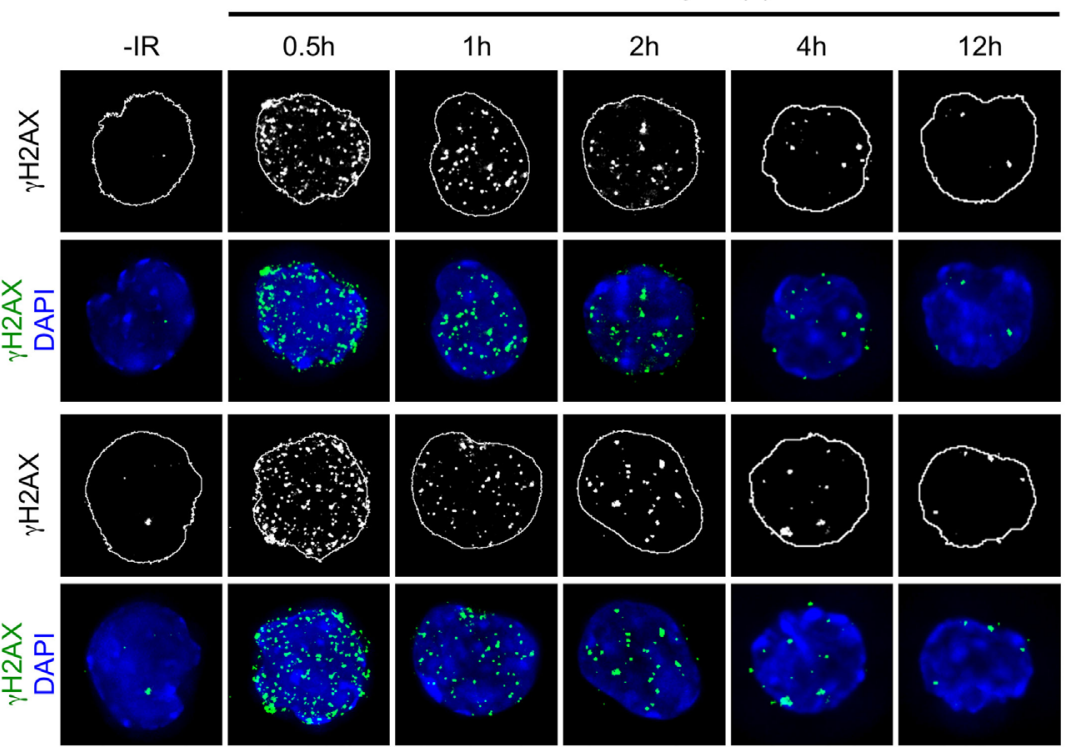

FIGURE 6 | Characterization of DN pro-T cells in vivo response to ionizing radiation (IR). (A) Number of DN1, DN2, and DN3 pro-T cells; (B) number of DN1 and DN2 pro-T cells only that were recovered at different time points $0-12 \mathrm{~h}$ after irradiation with 9 Gy. (C) Average number of $\gamma \mathrm{H} 2 \mathrm{AX}$ IR-induced foci (IRIF) per nucleus and (D) representative images of DN2 nuclei stained for $\gamma \mathrm{H} 2 \mathrm{AX} I \mathrm{RIF}$ and DAPI, corresponding to cells irradiated in vivo and isolated 0-12 h post IR. 
IRIF formation at only $30 \mathrm{~min}$ post IR. Remarkably, irradiated DN2 cells rapidly resolved these DNA DSBs, as indicated by the resolution of the majority of $\gamma \mathrm{H} 2 \mathrm{AX}$ IRIFs by $4 \mathrm{~h}$. As previously shown (Figures 6A,B), the numbers of DN1 and DN3 cells decreased dramatically post-IR due to cell death, and for DN1 cells, sufficient cells could not be recovered to carry out IRIF experiments. Since DN3 cells rapidly undergo apoptosis following IR, causing generalized $\gamma \mathrm{H} 2 \mathrm{AX}$ staining in their apoptotic nuclei, accurately quantifying $\gamma \mathrm{H} 2 \mathrm{AX}$ foci was not possible. In addition, it must be noted that all time-points referred to in this experiment correspond to the time when the thymi were isolated post IR and cell suspensions placed at $4^{\circ} \mathrm{C}$. The time elapsed during sample preparation and sorting until cells were fixed $(\sim 2 \mathrm{~h})$ is likely to underestimate the early kinetics of DNA damage repair in DN2 cells.

\section{DISCUSSION}

Following bone marrow transplantation (BMT), patients undergo a period of lymphopenia until their immune system is successfully regenerated. This lymphopenia renders them susceptible to life-threatening opportunistic infections and reactivation of endogenous viruses $(41,42)$. Although thymic cellularity drops drastically following irradiation due to the high radiosensitivity of the majority of thymocytes (15), many authors have reported a single wave of thymic auto-reconstitution occurring shortly after radiation exposure (16-20). Bosco et al. (21) determined that auto-reconstitution of the thymus was due to the survival of relatively radioresistant $\mathrm{CD} 25^{+}, \mathrm{CD} 44^{+}, \mathrm{CD} 117^{\text {high }}$ conventional DN2 pro-thymocytes capable of recapitulating normal thymic differentiation and generating a cohort of cells exported to the periphery. In addition, they suggested that their mature peripheral $\mathrm{T}$ cell progeny may act as a first barrier against infections during the lymphopenic periods that follow BMT (21). In fact, it has been shown that in some cases, host-derived anti-cytomegalovirus-specific $\mathrm{T}$ cells are able to protect patients against viral infection during the lymphopenic period following BMT (43). As shown by Bosco et al. (21) in mouse BM chimeras, host-derived $\mathrm{T}$ cells survive for at least 6 months (21), display a polyclonal TCR V $\beta$ repertoire, and appear to be functional both in vitro (17) and in vivo (21). To positively identify the DN2-derived cohort of $\mathrm{T}$ cells and distinguish them from their extra-thymically derived partners is difficult. However, since the thymic stroma is also irradiated in BM chimeras, it would be of interest to investigate the efficiency of negative selection of the TCR V $\beta$ repertoire amongst host thymus-derived T cells.

The mechanisms that mediate the radioresistance of DN2 thymocytes, in contrast to radiosensitive DN1 and DN3 thymocytes, are so far poorly characterized. One of the main difficulties to overcome in studying the radiobiology of DN cells at the molecular level is their low number (especially DN1 and DN2) in the normal mouse thymus. Therefore, in this study, we utilized "the Plastic Thymus" culture system to expand purified DN2 pro-T cells in vitro to study the role of the DDR in mediating their radioresistance. Overall, this study has demonstrated that (i) DN2 thymocytes activate a rapid DDR in response to IR-induced DNA DSBs, which in turn, (ii) is likely to contribute to their ability to induce a protective $\mathrm{G}_{1} / \mathrm{S}$ checkpoint and thereby, provide $\mathrm{DN} 2$ cells with a time window for repairing DNA DSBs, promoting their survival.

Developing $\mathrm{T}$ cells undergo a process of rearrangement of their TCR via $\mathrm{V}(\mathrm{D}) \mathrm{J}$ recombination, which begins during the DN1 to DN2 transition (44). V(D)J recombination is initiated by Rag-mediated DNA DSBs (45) that trigger the activation of the DDR and the subsequent repair of the lesions via NHEJ (46-48). The DDR pathway is crucial for lymphocyte development as demonstrated by the fact that deficiency or loss-of-function mutations in important DDR genes such as ATM, Nbs1, 53BP1, TopBP1, and DNA ligase IV cause multiple defects in lymphocyte development and function, resulting in aberrant $\mathrm{V}(\mathrm{D}) \mathrm{J}$ rearrangements, lymphopenia, and increased susceptibility to hematological malignancies (49-54). Interestingly, in this study, compared with HSC, DN2 thymocytes were found to express higher endogenous levels of key DDR sensor and NHEJ proteins, including ATM,

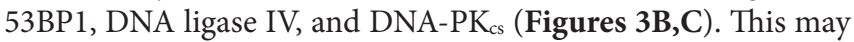
reflect the need for DN2 thymocytes to have a robust DDR in place for effective regulation of TCR gene rearrangements during early thymic development. Also, in lymphocytes, ATM and p53 have been directly implicated in limiting DSBs caused by V(D)J recombination exclusively to the $\mathrm{G}_{1}$ phase of the cell cycle (55), via the repression of Cyclin D3 expression (56). This mechanism, which is specific for developing lymphocytes and not observed in mature $\mathrm{T}$ cells, may explain the preferential activation of the $\mathrm{G}_{1} / \mathrm{S}$ checkpoint in DN2 pro-T cells in response to DNA damage. However, the $\mathrm{V}(\mathrm{D}) \mathrm{J}$ recombination process not only occurs in DN2 cells but also in more advanced stages of T cell development, as well as in pro-B cells (10), which are highly radiosensitive. Therefore, gene rearrangement alone is not sufficient to explain the unique radioresistance of DN2 cells, compared with other lymphoid progenitors that also execute $\mathrm{V}(\mathrm{D}) \mathrm{J}$ recombination.

In addition, in comparison with HSCs, DN2 cells also expressed particularly high levels of the pro-apoptotic factor Bim (Figure 5D). Bim is an important apoptotic mediator in thymocyte biology that has been shown to be crucial in many stages of $\mathrm{T}$ cell development, such as for the regulation of lymphocyte progenitor survival and negative selection (57-60). Furthermore, Bim activity is known to be crucial for inducing apoptosis in thymocytes in response to IR (61), and it has been shown to be highly expressed in thymocytes prior to pre-TCR expression, that is, at the DN3 stage, and is downregulated upon signaling through the pre-TCR (62). Therefore, our observation of high levels of Bim being expressed in DN2 thymocytes is in line with the literature in the field. These high levels of Bim would be lethal for the cells if they were not counteracted by high expression of anti-apoptotic proteins such as Bcl-2 [also in line with our results (Figure 3B), which is also highly expressed in DN pro-T cells and is downregulated at the DP stage $(63,64)]$. Interestingly, this high $\mathrm{Bcl}-2$ expression is dependent on IL-7, an indispensable cytokine for T lymphopoiesis, whose receptor IL7R $\alpha$ (CD127) is under the control of Notch 1 signaling $(65,66)$, two of the main components in "The Plastic Thymus" culture system.

In contrast to DN2 pro- $\mathrm{T}$ cells, HSCs are highly radiosensitive $(67,68)$. Here, we have characterized the DDR of NH-HSCs cultured in vitro and compared it to that of DN2 cells, showing 
that NH-HSCs display higher radiosensitivity than DN2 cells particularly at high IR doses (closer to those used as cytoreductive regimens prior to BMT) (Figure 1). Several aspects of their biology may be contributing to this effect, such as (i) their slower activation of the DDR pathway in response to IR, (ii) lower levels of expression of DDR factors that are important for NHEJ, (iii) differential DNA damage checkpoint activation compared with DN2 cells (Figures 2 and 3), and (iv) more rapid cell cycle kinetics. It would appear that cell cycle kinetics alone cannot explain the increased susceptibility of $\mathrm{NH}$-HSCs to irradiation. Strikingly, NH-HSCs from Bcl-2 transgenic mice, although retaining the same cell cycle kinetics as their non-Bcl-2 partners, did not undergo apoptosis following irradiation (unpublished observation). This indicates that the more rapid cell cycle kinetics of NH-HSC compared with DN2 cells was not responsible for their susceptibility to apoptosis. As previously shown by Bosco et al. (21), DN2 cells from Bcl-2 transgenic mice also showed dramatic changes in survival in vitro. Taken together, while the proliferation status of a given cell type may affect its radiosensitivity, we believe that our studies collectively suggest that the intrinsic orchestration of the DDR signaling pathway choice (i.e., induction of DNA damage checkpoints and DNA DSB repair versus cell death) plays a more important role in determining radiosensitivity. It would be of interest to compare the in vitro sensitivity of NH-HSC and DN2 thymocytes to glucocorticoids to help separate differences in their survival and DDR pathways. Previous experiments (20) had shown that host (presumably DN2)-derived thymocytes were seen in BM chimeras where recipient mice had been treated with hydrocortisone acetate $48 \mathrm{~h}$ prior to irradiation and BM reconstitution. This suggests that DN2 cells are glucocorticoid resistant in vivo. Animals treated with glucocorticoids and left to recover showed no sign of hematopoietic failure, suggesting indirectly that HSC and/ or multipotent progenitors do not appear to be glucocorticoid sensitive in vivo (20).

Interestingly, culturing $\mathrm{NH}-\mathrm{HSCs}$ under hypoxic conditions $\left(5 \% \mathrm{O}_{2}\right)$ increased the efficiency of DNA repair (Figure 5A) and suvival capacity (Figure 4; Figure S5 in Supplementary Material) in these cells, as well as inducing an important up-regulation of Bcl-2 protein levels (Figure 5D). By contrast, culture of DN2 cells in hypoxia resulted in less efficient DNA repair (Figure 5A) and decreased levels of DNA ligase IV and 53BP1 (Figure 5C) were detected in this condition. However, surface marker analysis of normoxic and hypoxic in vitro DN2 cultures demonstrated that, while DN2 cells cultured in normoxia maintain a stable phenotype, culturing the same cells in hypoxia results in the accumulation of a CD25- subpopulation that increases in number over time (data not shown). This fact makes it impossible to compare the DDR of DN2 cells in normoxia and in hypoxia, since in this last condition, a mixed population of $\mathrm{CD} 25^{+} \mathrm{DN} 2$-like cells and $\mathrm{CD}^{2} 5^{-}$cells of unknown nature are analyzed jointly and it is impossible to distinguish the specific contributions of each one to the overall result.

Despite these previous observations, DN2 pro-T cells cultured in vitro under normoxia retain many of their phenotypic and functional characteristics, which makes this culture system a very useful tool for the study of DN2 cells at the molecular level.
For this reason, it was important to also investigate whether the robust DDR activation and DNA DSB repair by DN2 thymocytes observed in vitro also occurs within the thymus itself (Figure 6). Cell numbers recovered from the thymus at different time-points post IR indicated that a higher proportion of DN2 thymocytes remain viable, in comparison with DN1 and DN3 thymocytes, whose numbers dropped quickly following IR exposure (Figures 6A,B). Surprisingly, cKit surface expression by DN cells was observed to decrease over time after IR (Figure S6 in Supplementary Material). Previous studies (69) have indicated that $c k i t$ is a target gene for Notch signaling. Therefore, the decrease in CD117 expression may be the result of decreased Notch ligand expression by TECs following irradiation (34).

Interestingly, DN2 pro-T cells displayed discrete, single, $\gamma \mathrm{H} 2 \mathrm{AX}$ IRIF in the absence of IR treatment (Figure 6D), which according to the observations from Chen et al. (52), may correspond to sites of $\mathrm{V}(\mathrm{D}) \mathrm{J}$ recombination-induced DSBs. Similar to the results obtained from DN2 cells in vitro, DN2 thymocytes ex vivo displayed fast activation of their DDR following IR, with $\gamma \mathrm{H} 2 \mathrm{AX}$ IRIF numbers peaking at $30 \mathrm{~min}$ post-IR. The quick disappearance of $\gamma \mathrm{H} 2 \mathrm{AX}$ IRIF, which was largely complete by $4 \mathrm{~h}$ after IR, is an indicator of the high efficiency in DSB repair displayed by DN2 cells in vivo. This is, to the best of our knowledge, the first time that the in vivo DNA repair efficiency of DN2 cells has been characterized.

In conclusion, we have used "The Plastic Thymus" in vitro culture system to investigate in detail the mechanisms responsible for the relatively high DN2 radioresistance that allows thymic auto-reconstitution following radiation exposure. We have shown that multiple facets of their DDR are likely to contribute to their enhanced survival in contrast to radiosensitive HSCs. Finally, we have demonstrated that DN2 pro-thymocytes are capable of efficiently repairing DNA DSBs in vivo following lethal thymic irradiation.

\section{ETHICS STATEMENT}

All animal experiments were carried out within institutional guidelines (authorization numbers 1886 and 1888 from Kantonales Veterinäramt, Basel).

\section{AUTHOR CONTRIBUTIONS}

IC-A and TS: conception and design, collection and assembly of data, data analysis and interpretation, and manuscript writing. NB: conception and design, data analysis and interpretation, manuscript writing, and final approval of manuscript. AR: conception and design, financial support, data analysis, and interpretation. RC: conception and design, financial support, data analysis and interpretation, manuscript writing, and final approval of manuscript.

\section{ACKNOWLEDGMENTS}

We dedicate this paper to the memory of our colleague, friend, group leader, and mentor Antonius Rolink. We would also like to acknowledge the support and generosity provided by the 
lab members of research groups based at NUI Galway and the University of Basel which made this highly fruitful collaboration possible.

\section{FUNDING}

The research leading to these results has been supported by the European Community's Seventh Framework Programme FP7/2007-2013 under grant agreement number 315902. TS and RC were supported by Science Foundation Ireland under grant numbers SFI09/SRC/B1794 and SFI07/SK/B1233b. TS

\section{REFERENCES}

1. Rieger MA, Schroeder T. Hematopoiesis. Cold Spring Harb Perspect Biol (2012) 4:1-18. doi:10.1101/cshperspect.a008250

2. Jagannathan-Bogdan M, Zon LI. Hematopoiesis. Development (2013) 140:2463-7. doi:10.1242/dev.083147

3. Chi AW, Bell JJ, Zlotoff DA, Bhandoola A. Untangling the T branch of the hematopoiesis tree. Curr Opin Immunol (2009) 21:121-6. doi:10.1016/j.coi. 2009.01.012

4. Zhao M, Li LH. Regulation of hematopoietic stem cells in the niche. Sci China Life Sci (2015) 58:1209-15. doi:10.1007/s11427-015-4960-y

5. Miller JFAP. Immunological function of the thymus. Lancet (1961) 2:748-9. doi:10.1016/S0140-6736(61)90693-6

6. Miller JFAP. The discovery of thymus function and of thymus-derived lymphocytes. Immunol Rev (2002) 185:7-14. doi:10.1034/j.1600-065X.2002. 18502.x

7. Manley NR, Richie ER, Blackburn CC, Condie BG, Sage J. Structure and function of the thymic microenvironment. Front Biosci (2011) 16:2461-77. doi: $10.2741 / 3866$

8. Alves NL, Takahama Y, Ohigashi I, Ribeiro AR, Baik S, Anderson G, et al. Serial progression of cortical and medullary thymic epithelial microenvironments. Eur J Immunol (2014) 44:16-22. doi:10.1002/eji.201344110

9. Boehm T, Bleul CC. Thymus-homing precursors and the thymic microenvironment. Trends Immunol (2006) 27:477-84. doi:10.1016/j.it.2006.08.004

10. Ceredig R, Rolink T. A positive look at double-negative thymocytes. Nat Rev Immunol (2002) 2:888-97. doi:10.1038/nri937

11. Alves NL, Huntington ND, Rodewald HR, Di Santo JP. Thymic epithelial cells: the multi-tasking framework of the T cell "cradle". Trends Immunol (2009) 30:468-74. doi:10.1016/j.it.2009.07.010

12. Anderson G, Takahama Y. Thymic epithelial cells: working class heroes for $\mathrm{T}$ cell development and repertoire selection. Trends Immunol (2012) 33:256-63. doi:10.1016/j.it.2012.03.005

13. Ceredig R, Dialynas DP, Fitch FW, MacDonald HR. Precursors of T cell growth factor producing cells in the thymus: ontogeny, frequency, and quantitative recovery in a subpopulation of phenotypically mature thymocytes defined by monoclonal antibody GK-1.5. J Exp Med (1983) 158:1654-71. doi:10.1084/ jem.158.5.1654

14. Godfrey DI, Zlotnik A, Suda T. Phenotypic and functional characterization of c-kit expression during intrathymic T cell development. J Immunol (1992) 149:2281-5.

15. Takada A, Takada Y, Huang CC, Ambrus JL. Biphasic pattern of thymus regeneration after whole-body irradiation. J Exp Med (1969) 129:445-57. doi:10.1084/jem.129.3.445

16. Kadish JL, Basch RS. Thymic regeneration after lethal irradiation evidence for an intra-thymic radioresistant T cell precursor. J Immunol (1975) 114:452-8.

17. Ceredig R, MacDonald HR. Phenotypic and functional properties of murine thymocytes. II. Quantitation of host- and donor-derived cytolytic T lymphocyte precursors in regenerating radiation bone marrow chimeras. J Immunol (1982) 128:614-20.

18. Zúñiga-Pflücker JC, Kruisbeek AM. Intrathymic radioresistant stem cells follow an IL-2/IL-2R pathway during thymic regeneration after sublethal irradiation. J Immunol (1990) 144:3736-40.

19. Thomas DB, Congdon CC. Spontaneous recovery in the thymus after supra-lethal whole-body x-irradiation. J Physiol (1967) 188:28-9. was supported by an EMBO Short-Term Fellowship (ASTF 339-2012) and an Irish Research Council Government of Ireland Embark Postgraduate Scholarship in Science, Engineering, and Technology (Grant No. RS20102702). AR was holder of the chair in immunology endowed by F. Hoffmann-La Roche Ltd., Basel.

\section{SUPPLEMENTARY MATERIAL}

The Supplementary Material for this article can be found online at https://www.frontiersin.org/articles/10.3389/fimmu.2018.01312/ full\#supplementary-material.

20. Ceredig R, Cummings DE. Phenotypic and functional properties of murine thymocytes. III. Kinetic analysis of the recovery of intrathymic cytolytic $\mathrm{T}$ lymphocyte precursors after in vivo administration of hydrocortisone acetate. J Immunol (1983) 130:33-7.

21. Bosco N, Swee LK, Bénard A, Ceredig R, Rolink A. Auto-reconstitution of the T-cell compartment by radioresistant hematopoietic cells following lethal irradiation and bone marrow transplantation. Exp Hematol (2010) 38:222-32. doi:10.1016/j.exphem.2009.12.006

22. Hare KJ, Jenkinson EJ, Anderson G. In vitro models of T cell development. Semin Immunol (1999) 11:3-12. doi:10.1006/smim.1998.0151

23. Basson MA, Zamoyska R. Insights into T-cell development from studies using transgenic and knockout mice. Methods Mol Biol (2000) 134:3-22. doi:10.1385/1-59259-682-7:3

24. Mohtashami M, Shah DK, Kianizad K, Awong G, Zúñiga-Pflücker JC. Induction of T-cell development by delta-like 4-expressing fibroblasts. Int Immunol (2013) 25:601-11. doi:10.1093/intimm/dxt027

25. Schmitt TM, Ciofani M, Petrie HT, Zúñiga-Pflücker JC. Maintenance of T cell specification and differentiation requires recurrent notch receptor-ligand interactions. J Exp Med (2004) 200:469-79. doi:10.1084/jem.20040394

26. Schmitt TM, Zúñiga-Pflücker JC. Induction of T cell development from hematopoietic progenitor cells by delta-like-1 in vitro. Immunity (2002) 17:749-56 doi:10.1016/S1074-7613(02)00474-0

27. Wang H, Pierce LJ, Spangrude GJ. Distinct roles of IL-7 and stem cell factor in the OP9-DL1 T-cell differentiation culture system. Exp Hematol (2006) 34:1730-40. doi:10.1016/j.exphem.2006.08.001

28. Tussiwand R, Engdahl C, Gehre N, Bosco N, Ceredig R, Rolink AG. The preTCR-dependent DN3 to DP transition requires Notch signaling, is improved by CXCL12 signaling and is inhibited by IL-7 signaling. Eur J Immunol (2011) 41:3371-80. doi:10.1002/eji.201141824

29. Gehre N, Nusser A, von Muenchow L, Tussiwand R, Engdahl C, Capoferri G, et al. A stromal cell free culture system generates mouse pro- $\mathrm{T}$ cells that can reconstitute T-cell compartments in vivo. Eur J Immunol (2015) 45:932-42. doi:10.1002/eji.201444681

30. Kastan MB, Bartek J. Cell-cycle checkpoints and cancer. Nature (2004) 432:316-23. doi:10.1038/nature03097

31. Harper JW, Elledge SJ. The DNA damage response: ten years after. Mol Cell (2007) 28:739-45. doi:10.1016/j.molcel.2007.11.015

32. Sugrue T, Calvo-Asensio I, Ceredig R. The radio-resistance of mesenchymal stromal cells and their potential role in the management of radiation injury. In: Atkinson K, editor. The Biology and Therapeutic Application of Mesenchymal Cells. Hoboken, New Jersey: John Wiley and Sons Inc. (2016). p. 391-414.

33. Sugrue T, Lowndes NF, Ceredig R. Mesenchymal stromal cells: radio-resistant members of the bone marrow. Immunol Cell Biol (2013) 91:5-11. doi:10.1038/ icb.2012.61

34. Calvo-Asensio I, Barthlott T, von Muenchow L, Lowndes NF, Ceredig R Differential response of mouse thymic epithelial cell types to ionizing radiation-induced DNA damage. Front Immunol (2017) 8:418. doi:10.3389/ fimmu.2017.00418

35. Sugrue T, Brown JAL, Lowndes NF, Ceredig R. Multiple facets of the DNA damage response contribute to the radioresistance of mouse mesenchymal stromal cell lines. Stem Cells (2013) 31:137-45. doi:10.1002/ stem. 1222

36. Sauvageau G, Thorsteinsdottir U, Eaves CJ, Lawrence HJ, Largman C, Lansdorp PM, et al. Overexpression of HOXB4 in hematopoietic cells causes 
the selective expansion of more primitive populations in vitro and in vivo. Genes Dev (1995) 9:1753-65. doi:10.1101/gad.9.14.1753

37. Ruedl C, Khameneh HJ, Karjalainen K. Manipulation of immune system via immortal bone marrow stem cells. Int Immunol (2008) 20:1211-8. doi:10.1093/ intimm/dxn079

38. von Muenchow L, Engdahl C, Karjalainen K, Rolink AG. The selection of mature B cells is critically dependent on the expression level of the co-receptor CD19. Immunol Lett (2014) 160:113-9. doi:10.1016/j.imlet.2014.01.011

39. Schindelin J, Arganda-Carreras I, Frise E, Kaynig V, Longair M, Pietzsch T, et al. Fiji: an open-source platform for biological-image analysis. Nat Methods (2012) 9:676-82. doi:10.1038/nmeth.2019

40. Sugrue T, Lowndes NF, Ceredig R. Hypoxia enhances the radioresistance of mouse mesenchymal stromal cells. Stem Cells (2014) 32:2188-200. doi:10.1002/ stem. 1683

41. Wingard JR, Hsu J, Hiemenz JW. Hematopoietic stem cell transplantation: an overview of infection risks and epidemiology. Infect Dis Clin North Am (2010) 24:257-72. doi:10.1016/j.idc.2010.01.010

42. Daikeler T, Tichelli A, Passweg J. Complications of autologous hematopoietic stem cell transplantation for patients with autoimmune diseases. Pediatr Res (2012) 71:439-44. doi:10.1038/pr.2011.57

43. Chalandon Y, Degermann S, Villard J, Arlettaz L, Kaiser L, Vischer S, et al. Pretransplantation CMV-specific T cells protect recipients of T-cell-depleted grafts against CMV-related complications. Blood (2006) 107:389-96. doi:10.1182/blood-2005-07-2746

44. Balciunaite G, Ceredig R, Fehling HJ, Zúñiga-Pflücker JC, Rolink AG. The role of Notch and IL-7 signaling in early thymocyte proliferation and differentiation. Eur J Immunol (2005) 35:1292-300. doi:10.1002/eji.200425822

45. Fugmann SD, Lee AI, Shockett PE, Villey IJ, Schatz DG. The RAG proteins and V(D)J recombination: complexes, ends, and transposition. Annu Rev Immunol (2000) 18:495-527. doi:10.1146/annurev.immunol.18.1.495

46. Bednarski JJ, Sleckman BP. Lymphocyte development: integration of DNA damage response signaling. Adv Immunol (2012) 116:175-204. doi:10.1016/ B978-0-12-394300-2.00006-5

47. Bednarski JJ, Sleckman BP. Integrated signaling in developing lymphocytes: the role of DNA damage responses. Cell Cycle (2012) 11:4129-34. doi:10.4161/ cc. 22021

48. Helmink BA, Sleckman BP. The response to and repair of RAG-mediated DNA double-strand breaks. Annu Rev Immunol (2012) 30:175-202. doi:10.1146/ annurev-immunol-030409-101320

49. Bredemeyer AL, Sharma GG, Huang C-Y, Helmink BA, Walker LM, Khor KC, et al. ATM stabilizes DNA double-strand-break complexes during V(D)J recombination. Nature (2006) 442:466-70. doi:10.1038/nature04866

50. Huang C-Y, Sharma GG, Walker LM, Bassing CH, Pandita TK, Sleckman BP. Defects in coding joint formation in vivo in developing ATM-deficient B and T lymphocytes. J Exp Med (2007) 204:1371-81. doi:10.1084/jem.20061460

51. Bowen S, Wangsa D, Ried T, Livak F, Hodes RJ. Concurrent V(D)J recombination and DNA end instability increase interchromosomal trans-rearrangements in ATM-deficient thymocytes. Nucleic Acids Res (2013) 41:4535-48. doi:10.1093/nar/gkt154

52. Chen HT, Bhandoola A, Difilippantonio MJ, Zhu J, Brown MJ, Tai X, et al. Response to RAG-mediated VDJ cleavage by NBS1 and gamma-H2AX. Science (2000) 290:1962-5. doi:10.1126/science.290.5498.1962

53. Nijnik A, Dawson S, Crockford TL, Woodbine L, Visetnoi S, Bennett S, et al. Impaired lymphocyte development and antibody class switching and increased malignancy in a murine model of DNA ligase IV syndrome. J Clin Invest (2009) 119:1696-705. doi:10.1172/JCI32743

54. Kim J, Lee SK, Jeon Y, Kim Y, Lee C, Jeon SH, et al. TopBP1 deficiency impairs $\mathrm{V}(\mathrm{D}) \mathrm{J}$ recombination during lymphocyte development. EMBO J (2014) 33: 217-28. doi:10.1002/embj.201284316

55. Dujka ME, Puebla-Osorio N, Tavana O, Sang M, Zhu C. ATM and p53 are essential in the cell-cycle containment of DNA breaks during V(D)J recombination in vivo. Oncogene (2010) 29:957-65. doi:10.1038/onc.2009.394
56. DeMicco A, Reich T, Arya R, Rivera-Reyes A, Fisher MR, Bassing CH. Lymphocyte lineage-specific and developmental stage specific mechanisms suppress cyclin D3 expression in response to DNA double strand breaks. Cell Cycle (2016) 15:2882-94. doi:10.1080/15384101.2016.1198861

57. Hernandez JB, Newton RH, Walsh CM. Life and death in the thymus - cell death signaling during T cell development. Curr Opin Biol (2011) 22:865-71. doi:10.1016/j.ceb.2010.08.003

58. Bouillet P, Purton JF, Godfrey DI, Zhang L-C, Coultas L, Puthalakath H, et al. BH3-only Bcl-2 family member Bim is required for apoptosis of autoreactive thymocytes. Nature (2002) 415:922-6. doi:10.1038/415922a

59. Gray DHD, Kupresanin F, Berzins SP, Herold MJ, O’Reilly LA, Bouillet P, et al. The BH3-only proteins Bim and Puma cooperate to impose deletional tolerance of organ-specific antigens. Immunity (2012) 37:451-62. doi:10.1016/j. immuni.2012.05.030

60. Pellegrini M, Bouillet P, Robati M, Belz GT, Davey GM, Strasser A. Loss of Bim increases $\mathrm{T}$ cell production and function in interleukin 7 receptor-deficient mice. J Exp Med (2004) 200:1189-95. doi:10.1084/jem. 20041328

61. Erlacher M, Michalak EM, Kelly PN, Labi V, Niederegger H, Coultas L, et al. $\mathrm{BH} 3$-only proteins Puma and Bim are rate-limiting for gamma-radiation- and glucocorticoid-induced apoptosis of lymphoid cells in vivo. Blood (2005) 106:4131-8. doi:10.1182/blood-2005-04-1595

62. Mandal M, Crusio KM, Meng F, Liu S, Kinsella M, Clark MR, et al. Regulation of lymphocyte progenitor survival by the proapoptotic activities of Bim and Bid. Proc Natl Acad Sci U S A (2008) 105:20840-5. doi:10.1073/pnas. 0807557106

63. Gratiot-Deans J, Merino R, Nuñez G, Turka LA. Bcl-2 expression during T-cell development: early loss and late return occur at specific stages of commitment to differentiation and survival. Proc Natl Acad Sci U S A (1994) 91:10685-9. doi:10.1073/pnas.91.22.10685

64. Gratiot-Deans J, Ding L, Turka LA, Nuñez G. bcl-2 proto-oncogene expression during human $\mathrm{T}$ cell development. Evidence for biphasic regulation. J Immunol (1993) 151:83-91.

65. Ceredig R, Rolink AG. The key role of IL-7 in lymphopoiesis. Semin Immunol (2012) 24:159-64. doi:10.1016/j.smim.2012.02.004

66. González-García S, García-Peydró M, Martín-Gayo E, Ballestar E, Esteller M, Bornstein R, et al. CSL-MAML-dependent Notch1 signaling controls $\mathrm{T}$ lineage-specific IL-7R $\{$ alpha $\}$ gene expression in early human thymopoiesis and leukemia. J Exp Med (2009) 206:779-91. doi:10.1084/jem.20081922

67. Meijne EI, van der Winden-van Groenewegen RJ, Ploemacher RE, Vos O, David JA, Huiskamp R. The effects of X-irradiation on hematopoietic stem cell compartments in the mouse. Exp Hematol (1991) 19:617-23.

68. Harfouche G, Martin MT. Response of normal stem cells to ionizing radiation: a balance between homeostasis and genomic stability. Mutat Res (2010) 704:167-74. doi:10.1016/j.mrrev.2010.01.007

69. Massa S, Balciunaite G, Ceredig R, Rolink AG. Critical role for c-kit (CD117) in $\mathrm{T}$ cell lineage commitment and early thymocyte development in vitro. Eur J Immunol (2006) 36:526-32. doi:10.1002/eji.200535760

Conflict of Interest Statement: Co-author NB is currently employed by Nestlé Research Center Asia. All other authors declare no competing interests. Co-author TS declares her affiliation with Frontiers and the handling Editor states that the process nevertheless met the standards of a fair and objective review. All other authors declare they have no potential conflicts of interests to disclose.

Copyright (C) 2018 Calvo-Asensio, Sugrue, Bosco, Rolink and Ceredig. This is an open-access article distributed under the terms of the Creative Commons Attribution License (CC BY). The use, distribution or reproduction in other forums is permitted, provided the original author(s) and the copyright owner are credited and that the original publication in this journal is cited, in accordance with accepted academic practice. No use, distribution or reproduction is permitted which does not comply with these terms. 